\title{
Caracterização espaço-temporal da qualidade das águas superficiais dos mananciais de abastecimento de Blumenau/SC
}

\author{
Spatio-temporal quality characterization of superficial waters from water supply in
} BlumenaulSC - Brazil

Submetido em: 28/03/17

Revisado em: 08/06/17 Aprovado em: 12/06/17

\section{Gustavo Antonio Piazza Suelen Cristina Grott Juliane Araújo Greinert Goulart Vander Kaufmann}

\section{RESUMO}

Este estudo teve como objetivo analisar a qualidade da água de quatro mananciais de abastecimento e em uma unidade conservação (UC), o parque nacional Serra do Itajaí, no município de Blumenau (SC). A ideia foi verificar a qualidade da água dos pontos utilizados para o abastecimento público do município, comparando-o com um cenário conservado. Treze campanhas de medição de parâmetros químicos foram executadas (08/2013-09/2014). Foram analisados os elementos acetato, cloreto, nitrato, fosfato, sulfato, potássio, magnésio, sódio, carbono orgânico total e carbono inorgânico. A estação ETA III e a UC parque nacional Serra do Itajaí, por estarem em local preservado apresentou resultados mais conservadores de qualidade. As outras ETAs por estarem sob maior influência antrópica tiveram um desempenho mais baixo em relação aos parâmetros descritores da qualidade de água.

Palavras-chave: Recursos hídricos, uso e ocupação do solo, fornecimento de água.

\section{ABSTRACT}

This study aims at analyzing the water quality from four water supply stations (ETA) and in a conservation unit (UC), Serra do Itajaí national park, in Blumenau (SC). Main idea was to verify the water quality of the points used for the public supply of the municipality, comparing it with a natural scenario (the national park). Thirteen measurement campaigns were carried out (08/2013-09/2014). The elements acetate, chloride, nitrate, phosphate, sulfate, potassium, magnesium, sodium, total organic carbon and inorganic carbon were analyzed. ETA III station and the Serra do Itajaí national park showed the best quality due to preservation. The other ETAs due to their higher anthropogenic influence, had a lower performance than the water quality descriptors.

Keywords: Water resources, land use, water supply.

\section{INTRODUÇÃO}

O processo de urbanização é acompanhado de alterações na ocupação do solo, que influenciam diretamente a qualidade dos recursos hídricos. A qualidade das águas consiste do efeito combinado de compartimentos (subterrâneo e superficial), processos naturais (chuva, escoamento, temperatura, entre outros) e influências antrópicas (provocadas tanto pela agricultura e como pela urbanização). Devido à complexidade dos produtos e subprodutos gerados pelas atividades humanas, o funcionamento dos sistemas naturais está sendo constantemente alterado. Influências mais comuns são os lançamentos de águas residuais nos corpos hídricos (LUOGON et al., 2009). Esses lançamentos são uma das influências negativas da sociedade contemporânea, a qual está alicerçada o desenvolvimento econômico (BUENO; GALBIATTI; BORGES, 2005) e os hábitos de consumo (MADRUGA; REIS; MEDEIROS, 2008). 
As transformaçóes causadas nos corpos hídricos pela urbanização são mensuradas e diagnosticadas pelo monitoramento da qualidade das águas superficiais (MONTEIRO; PINHEIRO, 2004; SOUZA; MELLO, 2012; PINHEIRO et al., 2014). Esse monitoramento é um dos principais instrumentos de planejamento e gestão de recursos hídricos, visto que funciona como ferramenta de apoio a tomada de decisão (GUEDES et al., 2012). De acordo com Simeonov et al. (2003), um programa de monitoramento ambiental inclui, em geral, coletas frequentes nos mesmos locais de amostragem, análises em laboratório de parâmetros representativos de suas características físicas, químicas e biológicas, além do tratamento das séries de dados.

O processo de urbanização do município de Blumenau, como da maioria das cidades brasileiras, teve um processo de urbanização sem planejamento das possíveis consequências sobre os recursos hídricos. No caso de Blumenau, a cidade foi colonizada em meados do século XIX por imigrantes alemães. De acordo com Budag (2004), a influência da colonização estrangeira e o processo de colonização por meio da iniciativa privada iniciada pelo Dr. Hermann Bruno Otto Blumenau, delinearam uma forma própria de organização e de ocupação do espaço. Somado a isso, tem-se as condicionantes naturais, cuja geomorfologia é caracterizada por uma topografia acidentada, com encostas que apresentam grande amplitude e inclinaçáo, permeadas por uma complexa rede de drenagem. Tem-se, portanto, uma malha urbana compartimentada por morros e cujas principais vias margeiam rios e ribeiróes, visto que a ocupação urbana ocorreu ao longo dos fundos de vale. Devido a isso, a cidade sofre com problemas frequentes relacionados a enchentes e inundaçôes (FRANK; AUMMOND, 2009), além dos aportes de poluentes aos cursos de água.

Tendo em vista a importância dos mananciais públicos de abastecimento do município de Blumenau (SC), foram realizadas treze (13) campanhas mensais de medição de concentração de parâmetros químicos entre 08/2013 a 09/2014, com objetivo de verificar sua qualidade. As coletas foram realizadas nas tubulações de captação, contendo água bruta não tratada (água de entrada), nas quatro estaçóes de Tratamento de Água (I, II, III, IV) e em uma unidade de conserva- ção (UC) parque nacional Serra do Itajaí, totalizando um total de cinco seçóes de monitoramento.

\section{MATERIAIS E MÉTODOS}

\section{Área de estudo}

O estudo foi realizado no município de Blumenau, localizado na Bacia do Itajaí-Açú, no estado de Santa Catarina, sul do Brasil. Blumenau possui uma população estimada de 334.002 hab., distribuída em uma área territorial de $518,497 \mathrm{~km}^{2}$ e densidade demográfica de 595,9 hab/ $\mathrm{km}^{2}$, dos quais $92,4 \%$ vivem em área urbana (IBGE, 2014).

O monitoramento da qualidade de água foi realizado nos pontos de captaçáo das quatro estaçóes de tratamento de água (ETA) do município, operadas pelo Serviço Autônomo Municipal de Água e Esgoto - SAMAE, e na seção fluviométrica do Ribeirão Garcia que se encontra inserido em uma unidade de conservação (UC) ambiental (parque nacional Serra do Itajaí) (Figura 1). O parque nacional da Serra do Itajaí situa-se inteiramente no Vale do Itajaí, em Santa Catarina, abrangendo uma área de 57.374 ha de Mata Atlântica, distribuídos em nove municípios: Ascurra, Apiúna, Blumenau, Botuverá, Gaspar, Guabiruba, Indaial, Presidente Nereu e Vidal Ramos. Foi instituído através de Decreto Federal, emitido pela Presidência da República em 4 de junho de 2004, sendo sua administração operada pelo Instituto Chico Mendes de Conservação da Biodiversidade (ICMBio).

A ETA I localiza-se na regiáo central do município, no Rio Itajaí-Açú (Figura 1), maior bacia da vertente atlântica do estado (16,5\% da área territorial). A ETA I opera desde 1943 com uma capacidade de produção de $60{\mathrm{~L} . \mathrm{s}^{-1}}^{\mathrm{e}}$ funcionamento de 12 horas diárias (SAMAE, 2014). A área de drenagem até a ETA I é de aproximadamente cerca de $12000 \mathrm{~km} 2$, sendo que 45 municípios estáo localizados a montante desta ETA, com aproximadamente 870.000 hab. O principal uso do solo a montante é agricultura familiar não intensiva. A ETA II, segue as mesmas características da ETA I, pois elas são próximas em distância. A ETA II se localiza no Rio Itajaí-Açú, a montante da ETA I (Figura 1), operando desde 1970 com uma capacidade de $840 \mathrm{~L} . \mathrm{s}^{-1}$, funcionando 24 horas diárias (SAMAE, 2014). A área de drenagem das bacias contribuintes é de cerca de $12000 \mathrm{~km} 2$, 
com 45 municípios e uma população estimada de 870.000 hab localizadas a montante. O principal uso do solo é agricultura familiar não intensiva. A ETA III localiza-se na bacia hidrográfica do Ribeirão Garcia (Figura 1), que é afluente da margem direita do Rio Itajaí-Açú, e possui uma área de drenagem de $158 \mathrm{~km}^{2}$. A ETA III opera desde 1997 com uma capacidade de produção de $400 \mathrm{~L} \cdot \mathrm{s}^{-1}$ e funcionamento de 24 horas diárias (SAMAE, 2014). Não existe nenhuma cidade a montante desta bacia, pois ela se encontra inteiramente dentro do município de Blumenau. A montante da ETA III encontra-se a UC parque nacional Serra do Itajaí. Desta forma, poucos habitantes se encontram a montante desta seção. A bacia caracteriza-se por ser uma bacia protegida por Floresta Ombrófila Densa conservada, com alguns usos agrícolas nas margens. Por final, a ETA IV localiza-se em uma bacia de pequeno porte no norte do município de Blumenau (Figura 1), no Ribeirão
Itoupava Rega (pertencente à bacia do Itapocú), com uma área de drenagem de $31 \mathrm{~km}^{2}$. A ETA IV opera desde 1995 e tem uma capacidade de produção de

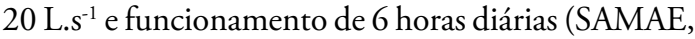
2014). Náo existe nenhuma cidade a montante desta bacia, pois ela se encontra inteiramente dentro do município de Blumenau. Esta bacia se caracteriza por ser uma bacia urbanizada, com populaçáo ocupando grande parte de suas margens.

O clima da região é, de acordo com a classificação de Köppen, Cfa - temperado úmido, com verão quente (ALVARES et al., 2013), caracterizado por verôes quentes e chuvosos, com umidade relativa alta. A região tem distribuição pluviométrica bastante regular e uniforme ao longo do ano, não havendo período de estiagem definido. A temperatura média anual é de $18,9^{\circ} \mathrm{C}$ e a precipitação média anual é de $1.574,5 \mathrm{~mm}$ (EPAGRI, 2002).

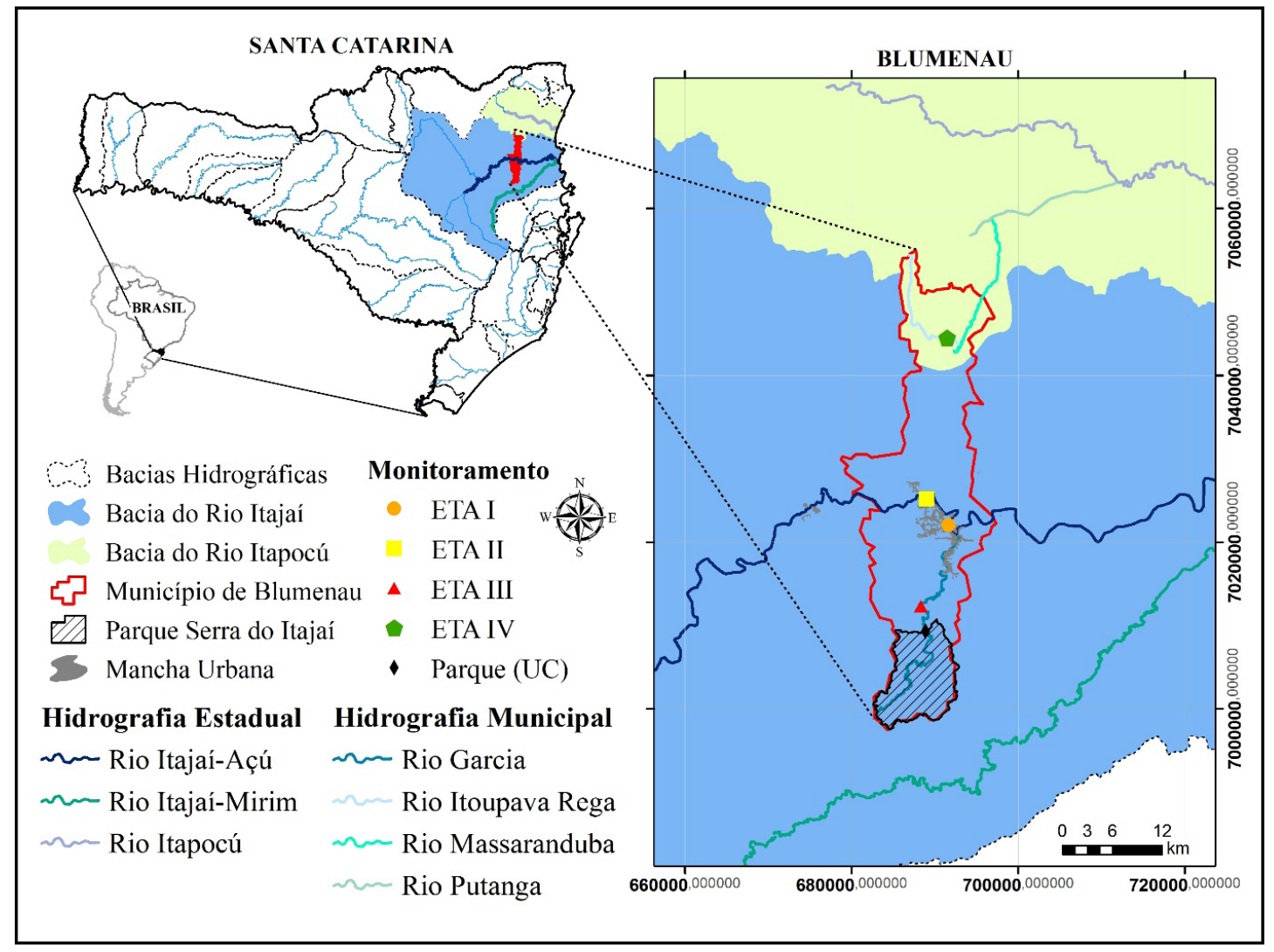




\section{MAPAS DE LOCALIZAÇÃO E CLASSIFICAÇÃO DA OCUPAÇÃO DO SOLO}

Os mapas de localização das bacias hidrográficas foram gerados em Sistemas de Informação Geográfica (SIG). Primeiramente, foi coletada em campo, a partir de um aparelho de GPS (Global Positioning System) Garmin GPSMAP 76CSx (precisão de 2-3m), de forma estática, a posição geográfica das estações de tratamento de água e o local de coleta no parque nacional Serra do Itajaí, no sentido de posicionar estes locais sobre a base cartográfica. As bases utilizadas abrangem os municípios de Blumenau, Pomerode e Botuverá, com escala de 1:50.000 (disponível em endereço eletrônico da EPAGRI/CIRAM-SC). Os dados foram manuseados no software ArcGIS ${ }^{\circledR}$ 10.1.

O mapa de uso e ocupação do solo da bacia hidrográfica da ETA I/ETA II teve como base o mapa de remanescentes florestais da NATURE (2005) devido ao tamanho $\left(11730 \mathrm{~km}^{2}\right)$ e a complexidade da bacia (mescla de usos). Bacias grandes e fragmentadas pelo uso do solo, tornam a classificação de imagens um processo complexo e lento. Para as ETA III e ETA IV por serem bacias pequenas foi realizada uma classificação de forma supervisionada, a partir da imagem de satélite LANDSAT 5 ETM+ (ano 2011), com resolução espacial de $30 \mathrm{~m}$. Neste caso, a imagem foi preliminarmente segmentada no software eCognition ${ }^{\circledR} 8$. Em seguida, classificou-se em duas classes, área florestada e área não florestada (outros).

\section{MÉTODOS DE COLETA E ANÁLISE DE DADOS}

Foram realizadas 13 campanhas de medição de concentração de parâmetros químicos, no período compreendido entre 08/2013 a 09/2014. As coletas foram realizadas na tubulação de captação (entrada de água da ETA), contendo água bruta não tratada. $\mathrm{Na}$ área do parque nacional a coleta se deu diretamente na seção fluviométrica. Em cada ponto de monitoramento foram coletadas amostras de águas em potes para determinação das concentraçóes em laboratório de acetato, cloreto, nitrato, fosfato, sulfato, potássio, magnésio, sódio, carbono orgânico total (COT) e carbono inorgânico $(\mathrm{CI})$. Os potes utilizados para coleta foram pré-lavados com solução de eluição assim como todo o material de laboratório. As amostras de água foram recolhidas de acordo com APHA (1998), mantidas refrigeradas durante o transporte e processadas em $24 \mathrm{~h}$.

Para verificar a ocorrência dos analitos utilizou-se de duas técnicas analíticas. Foi utilizada a Cromatografia de Troca Iônica (IC) para determinação de cátions e ânions e o Analisador de Carbono Total (Shimadzu TOC 500 - TOC analyzer) para as formas de carbono total (CT), carbono orgânico total (COT) e carbono inorgânico (CI). Os cátions e ânions seguiram metodologias propostas pela DIONEX (2010a) para ânions e DIONEX (2010b) para cátions.

No sentido de verificar a correlação das concentraçóes com os dados de pluviometria foram utilizados dados de precipitaçáo da estação PCD Blumenau (Código ANA 02649007), localizada no município de Blumenau. Foram utilizados dados pluviométricos mensais, disponíveis na plataforma hidroweb (http:// hidroweb.ana.gov.br), da Agência Nacional de Águas.

Utilizou-se também a análise de componentes principais e a análise agrupamentos (cluster), que são técnicas multivariadas que permitem correlacionar e classificar um conjunto de dados de observação. Como unidade de distância, optou-se por usar o quadrado da distância euclidiana, conforme Moura, Boaventura e Pinelli (2010). Ambas as técnicas foram executadas com o software PAST.

\section{RESULTADOS E DISCUSSÃO}

\section{Uso e ocupação do solo das bacias}

As ETAs I e II (Figura 2) são as estaçóes de tratamento que mais sofrem influência antrópica devido à sua extensão em usos e área de drenagem. Nessas ETAs existem aproximadamente 45 municípios a montante, sendo que muitos destes possuem centros municipais e extensas áreas agrícolas.

O uso do solo até o local analisado da ETA I e II é de $55,72 \%$ de florestas nativas e 44,28\% de outros usos (áreas urbanas, agricultura, entre outros). $\mathrm{Na}$ ETA III o cenário é mais conservador, com uma área total de $87,35 \mathrm{~km}^{2}$, sendo destes $97,19 \%$ de áreas de floresta nativa e apenas $2,81 \%$ referentes a outros usos. A situação do parque nacional é ainda mais conservadora, pois o local é uma UC protegida por lei; 


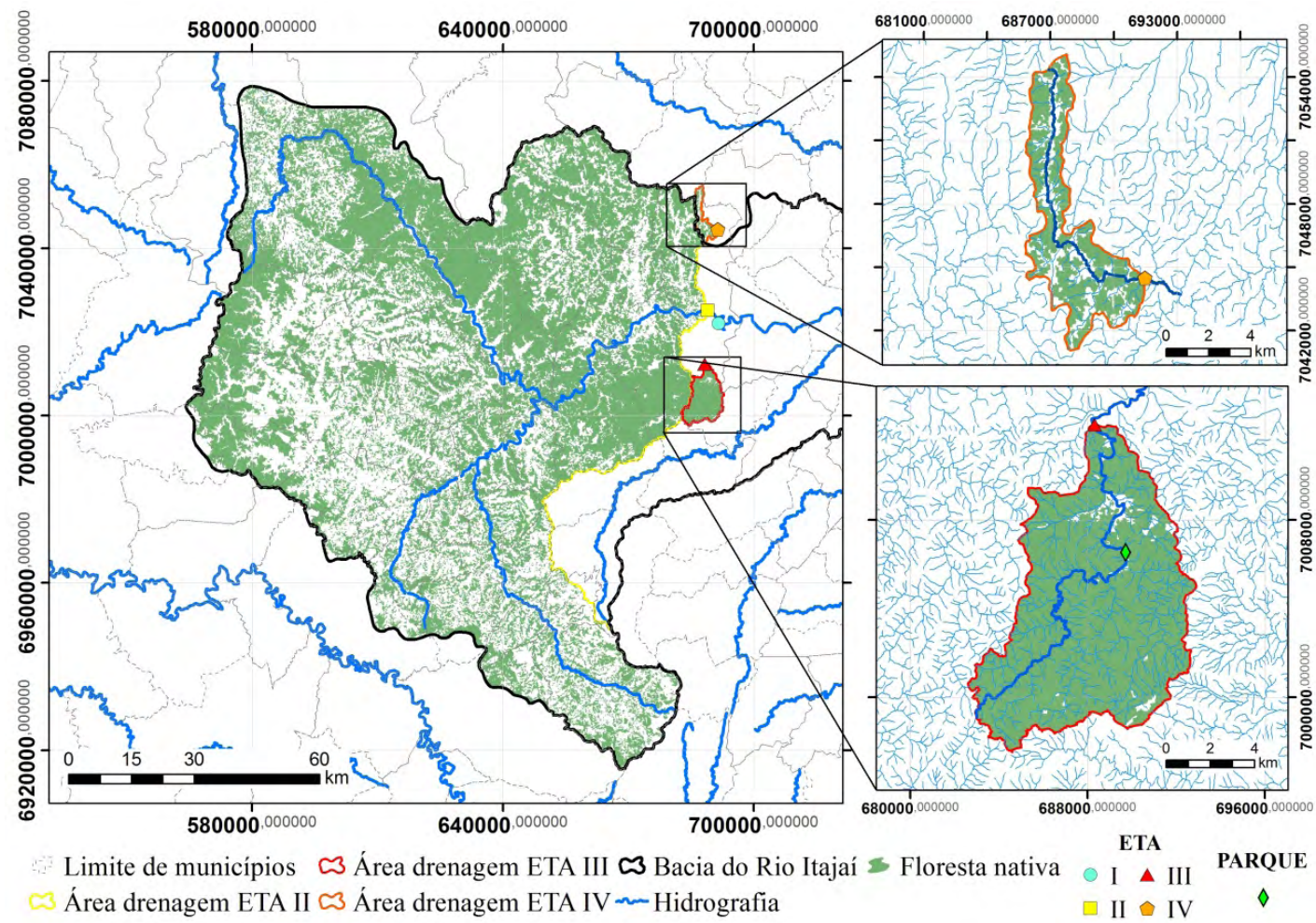

Figura 2 - Uso e ocupação do solo das áreas de drenagem das estações de tratamento de água no município de Blumenau, Santa Catarina - Brasil

com $61,95 \mathrm{~km}^{2}$ de área total, sendo que $99,06 \%$ são cobertos por floresta nativa e $0,94 \%$ por outros usos. A bacia da ETA IV é a menor dentre as estudadas, com apenas $30,82 \mathrm{~km}^{2}$, sendo que destes $67,92 \%$ são áreas de floresta nativa e $32,07 \%$ são de outros usos.

\section{Precipitação da estação PCD Blumenau}

A precipitação na região do Vale do Itajaí é uma das variáveis meteorológicas mais importantes tendo em vista o histórico da regiáo, sendo que desde sua colonização a cidade sofre com problemas frequentes relacionados a enchentes e inundaçóes (FRANK; AUMMOND, 2009). A média anual tendo em vista os dados da estação PCD de Blumenau para o período de 1945 a 2000 é de $1550 \mathrm{~mm}$. A estação mais chuvosa é o verão com média de $565 \mathrm{~mm}$, seguida da primavera com $405 \mathrm{~mm}$. O outono é a estação mais seca com $284 \mathrm{~mm}$ e o inverno com $325 \mathrm{~mm}$. O verão

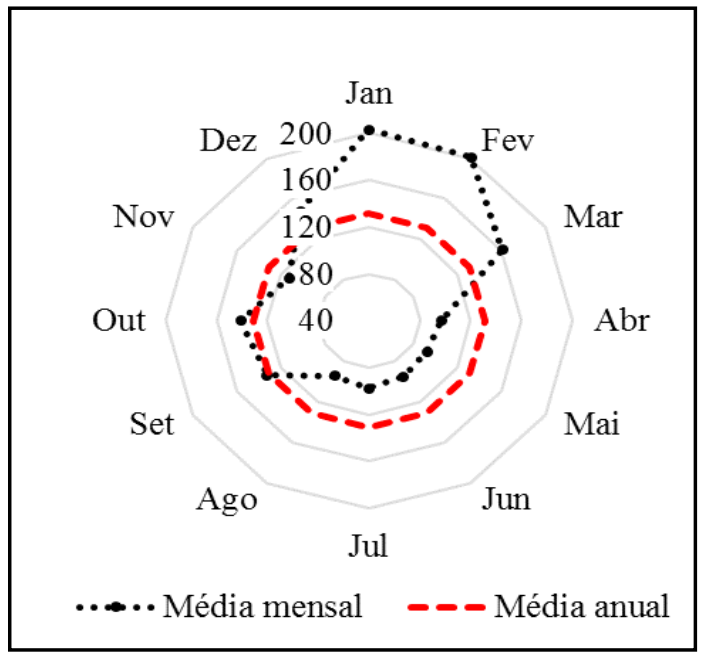

Figura 3 - Distribuição de chuva por mês e mensal anual da precipitação na estação PCD de Blumenau (dados de 1945 - 2015) 
é marcado por eventos de chuvas de curta duração e de alta intensidade e o inverno por períodos secos e com eventos de longa duração e menor intensidade. Na Figura 3 é apresentado o comportamento mensal das chuvas da estação analisada.

\section{CONCENTRAÇÕES DE ELEMENTOS}

$\mathrm{Na}$ Figura 4 são apresentadas as evoluçôes temporais das concentraçóes das espécies químicas analisadas em cada ponto de coleta.

Em relação às médias, para o acetato (ânion natural encontrado em solução aquosa), a maior média foi encontrada para o parque nacional Serra do Itajaí $\left(0,0051 \mathrm{mg} / \mathrm{L}^{-1}\right)$, sendo que a ETA III, próxima do parque nacional, aparece como a segunda maior média $\left(0,0042 \mathrm{mg} / \mathrm{L}^{-1}\right)$. A ETA IV $\left(0,0027 \mathrm{mg} / \mathrm{L}^{-1}\right)$ apresentou a terceira maior média, acompanhada da ETA I $\left(0,0022 \mathrm{mg} / \mathrm{L}^{-1}\right)$ e ETA II $\left(0,0018 \mathrm{mg} / \mathrm{L}^{-1}\right)$. A ETA III e o parque nacional Serra do Itajaí foram os pontos com os maiores valores de concentração de acetato $0,0319 \mathrm{mg} / \mathrm{L}^{-1}$ e $0,0469 \mathrm{mg} / \mathrm{L}^{-1}$, respectivamente (Figura 4). Este fato pode ter ocorrido, pois o parque nacional Serra do Itajaí e a ETA III se localizam em áreas conservadas, sendo que concentraçóes deste elemento podem ser influenciadas pela decomposição da matéria orgânica, como ciclagem de nutrientes provenientes da serapilheira (depósito de folhas e galhos no solo) e carregados pelo escoamento superficial.

$\mathrm{O}$ cloreto $(\mathrm{Cl}-)$ pode ter proveniência natural (depósitos salinos) e antrópica (efluentes industriais ou urbanos). As maiores médias para o $\mathrm{Cl}$ - foram encontradas na ETA II $\left(2,92 \mathrm{mg} \mathrm{L}^{-1}\right)$ e ETA I $(2,42$ $\left.\mathrm{mg} \mathrm{L}^{-1}\right)$. A ETA III e ETA IV apresentaram valores menores, de 1,83 e $1,76 \mathrm{mg} \mathrm{L}^{-1}$, respectivamente. $\mathrm{O}$ parque nacional Serra do Itajaí apresentou a menor média (1,69 $\left.\mathrm{mg} \mathrm{L}^{-1}\right)$ (Figura 4).

$\mathrm{O}$ nitrato (NO3) é uma das formas presentes do nitrogênio na água. Ele é um composto indispensável ao crescimento de plantas e algas, porém, em excesso, ocasiona o desenvolvimento acentuado de organismos. $\mathrm{O}$ excesso de $\mathrm{NO} 3$, geralmente, é proveniente de lançamentos de esgotos sanitários ou pelo uso indevido de fertilizantes em áreas agrícolas (Esteves, 2011). Nos resultados, a ETA I $\left(9,21 \mathrm{mg} \mathrm{L}^{-1}\right)$, ETA III (7,98 $\left.\mathrm{mg} \mathrm{L}^{-1}\right)$ e a ETA II $\left(7,61 \mathrm{mg} \mathrm{L}^{-1}\right)$ apresentaram as maiores concentraçóes médias, sendo que a ETA IV e o parque nacional Serra do Itajaí apresentaram médias mais baixas, 6,70 $\mathrm{mg} \mathrm{L}^{-1}$ e $6,69 \mathrm{mg} \mathrm{L}^{-1}$, respectivamente (Figura 4). É importante salientar que durante as coletas houveram valores elevados, como $57,43 \mathrm{mg} \mathrm{L}^{-1}$ (ETA II), 52,28 $\mathrm{mg} \mathrm{L}^{-1}$ (parque nacional Serra do Itajaí), 47,18 $\mathrm{mg} \mathrm{L}^{-1}$ (ETA III) e 44,44 mg $\mathrm{L}^{-1}$ (ETA I).

O fosfato (PO43-) ocorre nas águas superficiais por descargas de esgotos domésticos, constituídos de matéria orgânicas fecais e detergentes (CETESB, 2009). Neste estudo, os valores médios de PO43foram de $0,58 \mathrm{mg} \mathrm{L}^{-1}$ para a ETA I, $0,29 \mathrm{mg} \mathrm{L}^{-1}$ para a ETA II, 0,27 $\mathrm{mg} \mathrm{L}^{-1}$ para a ETA III, $0,17 \mathrm{mg} \mathrm{L}^{-1}$ para ETA IV e $0,11 \mathrm{mg} \mathrm{L}^{-1}$ para o parque nacional Serra do Itajaí (Figura 4). A ocorrência do composto químico foi determinada pela maior quantidade de atividades antrópicas a montante da estação, sendo as ETA I e ETA II próximas da mancha urbana.

O sulfato (SO42-) é um dos íons mais abundantes na natureza, tendo como fonte natural à dissolução de solos/rochas e a deposição atmosférica (ROCHELLE; CHURCH; DAVID, 1987; KATZ, 1989; RICE; BRICKER, 1995; PETERS et al., 2006). Em relação as fontes antrópicas, o SO42- está presente em descargas de esgotos domésticos e efluentes industriais (MOURA; BOAVENTURA; PINELLI, 2010). É importante o controle do SO42- na água tratada, pois a sua ingestão tem efeito laxativo no corpo humano. Em relação aos valores encontrados, as maiores médias foram para a ETA II $\left(1,50 \mathrm{mg} \mathrm{L}^{-1}\right)$ e ETA I $(1,49 \mathrm{mg}$ $\left.\mathrm{L}^{-1}\right)$, os outros pontos ETA III, parque nacional Serra do Itajaí e ETA IV apresentaram 0,69 $\mathrm{mg} \mathrm{L}^{-1}, 0,63$ $\mathrm{mg} \mathrm{L}^{-1}$ e $0,49 \mathrm{mg} \mathrm{L}^{-1}$, respectivamente.

O sódio $(\mathrm{Na})$ é abundante no planeta terra (LUCAS et al., 2014), sendo principalmente proveniente da dissolução tipos de argila na ausência de fontes antropogênicas (BOWSER; JONES, 2002). Nas coletas, a maior média de concentração de sódio foi para a ETA II $\left(3,64 \mathrm{mg} \mathrm{L}^{-1}\right)$, com valores similares para a ETA I $\left(3,42 \mathrm{mg} \mathrm{L}^{-1}\right)$, parque nacional Serra do Itajaí $\left(3,35 \mathrm{mg} \mathrm{L}^{-1}\right)$, ETA IV $\left(3,28 \mathrm{mg} \mathrm{L}^{-1}\right)$ e ETA III $\left(2,13 \mathrm{mg} \mathrm{L}^{-1}\right)$. As concentraçóes de sódio nas águas superficiais, entretanto, variam dependendo das condiçôes geológicas e das características industriais locais. Os valores médios de concentração obtidos são 


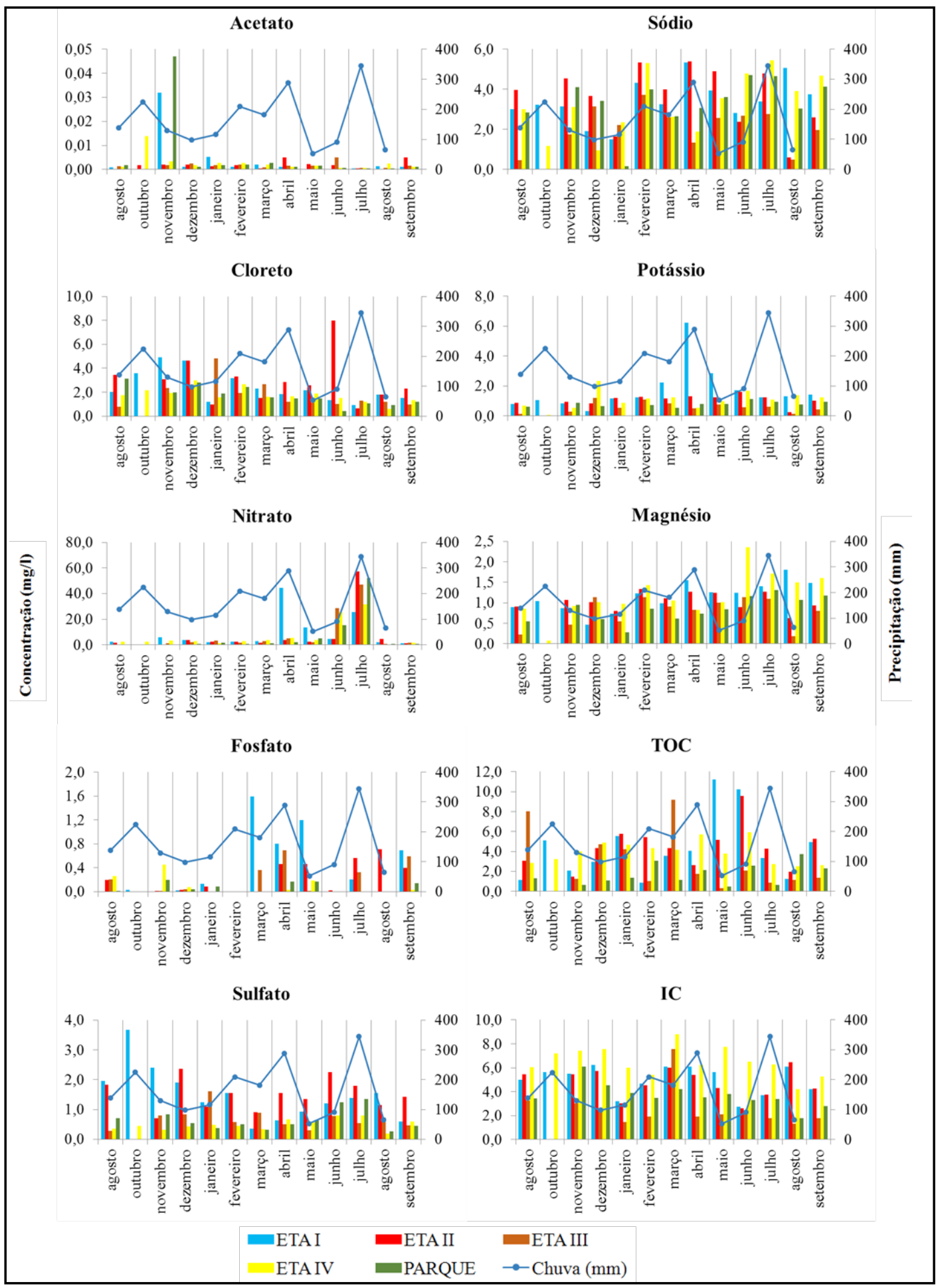

Figura 4 - Comportamento das concentrações das espécies químicas analisados nos mananciais das estações de tratamento de água juntamente com os dados de chuva da estação PCD de Blumenau 
de mesma ordem de grandeza em todos os pontos, não caracterizando a influência do uso e da ocupaçáo do solo.

Fontes de potássio $(\mathrm{K})$ são atribuídas à dissolução (BOWSER; JONES, 2002; BRADY; WEIL, 2008). $O$ potássio tem alta solubilidade e é facilmente lixiviado da matéria orgânica, assim, sua concentração nos cursos de água é afetado pela decomposição da matéria orgânica (MARKEWITZ; RICHTER, 2000). A ocorrência do potássio foi maior na ETA I $\left(1,72 \mathrm{mg} \mathrm{L}^{-1}\right)$, em seguida ETA II $\left(1,07 \mathrm{mg} \mathrm{L}^{-1}\right)$, ETA IV (1,06 $\left.\mathrm{mg} \mathrm{L}^{-1}\right)$, parque nacional Serra do Itajaí $\left(0,73 \mathrm{mg} \mathrm{L}^{-1}\right)$ e ETA III $\left(0,58 \mathrm{mg} \mathrm{L}^{-1}\right)$. A sequência das concentraçóes foi novamente determinada de acordo com a conservação de áreas de floresta nativa (maiores na ETA III e parque nacional Serra do Itajaí). As concentraçóes naturais são provenientes de processos de lixiviação da matéria orgânica por escoamento superficial (MARKEWITZ; RICHTER, 2000; BOWSER; JONES, 2002).

O magnésio $(\mathrm{Mg})$, assim como o cálcio $(\mathrm{Ca})$, é proveniente de fonte geológica, que pelo escoamento superficial ou pela drenagem alimentam os lençóis freáticos e ribeirôes. A maior concentração de magnésio foi encontrada na ETA IV $\left(1,18 \mathrm{mg} \mathrm{L}^{-1}\right)$, em seguida ETA I (1,15 $\left.\mathrm{mg} \mathrm{L}^{-1}\right)$, ETA II $\left(1,04 \mathrm{mg} \mathrm{L}^{-1}\right)$, parque nacional Serra do Itajaí $\left(0,84 \mathrm{mg} \mathrm{L}^{-1}\right)$ e ETA III $\left(0,79 \mathrm{mg} \mathrm{L}^{-1}\right)$, tendo como possível proveniência a proximidade de centros urbanos.

O carbono orgânico total (COT) é a aquele proveniente de fontes naturais (parte biodegradável), tendo origem na decomposição de plantas/animais, fezes e o sólidos em suspensão da água. $\mathrm{O}$ carbono inorgânico (CI) por sua vez considera as parcelas náo biodegradáveis da matéria, proveniente tanto de processos naturais como antrópicos. Neste estudo o COT foi maior para a ETA II $\left(4,44 \mathrm{mg} \mathrm{L}^{-1}\right)$, em sequencial a ETA I $\left(4,32 \mathrm{mg} \mathrm{L}^{-1}\right)$, ETA IV $(3,95 \mathrm{mg}$ $\left.\mathrm{L}^{-1}\right)$, ETA III $\left(2,98 \mathrm{mg} \mathrm{L}^{-1}\right)$ e parque nacional Serra do Itajaí (1,70 $\left.\mathrm{mg} \mathrm{L}^{-1}\right)$. Este fato apenas confirma a alta incidência de aporte orgânico nas regióes com alta ocorrência de atividades antrópicas, como ETA I e II. Para o CI, a ETA IV (6,51 $\left.\mathrm{mg} \mathrm{L}^{-1}\right)$ apresentou o maior valor, sequencialmente seguido da ETA I (4,99 $\left.\mathrm{mg} \mathrm{L}^{-1}\right)$, ETA II $\left(4,75 \mathrm{mg} \mathrm{L}^{-1}\right)$, parque nacional Serra do Itajaí $\left(3,68 \mathrm{mg} \mathrm{L}^{-1}\right)$ e ETA III $\left(2,56 \mathrm{mg} \mathrm{L}^{-1}\right)$. O maior valor de carbono inorgânico na ETA IV pode ser explicado pelo uso do solo (Figura 2), que por ser uma bacia de pequeno porte e com alta incidência de atividade humana tem alta ocorrência de fontes de carbono.

O comportamento dos valores discutidos acima foi sintetizado na tabela 1 .

Foi observado que as bacias de grande porte (mais complexas, mais fragmentadas) foram responsáveis pelas maiores concentraçóes das espécies químicas. Este fato nos leva a inferir que bacias hidrográficas de grande porte podem ser mais difíceis de gerir, pois as águas são provenientes de outras cidades com diferentes fontes de poluição (pontuais e difusas) e diferentes usos do solo. Além disso, uma maior área de drenagem significa uma maior permanência de água e maior enriquecimento de íons. Vale a pena notar que mesmo para elementos naturais de ordem geológica, como o sódio, magnésio e até mesmo o potássio, são maiores para bacias com maior influência antrópica, ou seja, aportes naturais destes elementos são complementados por fontes antrópicas.

Utilizando a análise de componentes principais, as estaçóes ETA I e ETA II (maiores concentraçóes das espécies químicas) apresentaram correlação

Tabela 1 - Ordem dos valores médios de concentração das estações de tratamento e elementos analisados, referente à Blumenau - Santa Catarina

\begin{tabular}{ccccccccccc}
\hline Elemento & Acetato & Cloreto & Nitrato & Fosfato & Sulfato & Sódio & Potássio & Magnésio & COT & IC \\
\hline maior & P & II & I & I & II & II & I & IV & II & IV \\
$\uparrow$ & III & I & III & II & I & I & II & I & I & I \\
Concentração & IV & III & II & III & III & P & IV & II & IV & II \\
$\downarrow$ & I & IV & IV & IV & P & IV & P & P & III & P \\
menor & II & P & P & P & IV & III & III & III & P & III \\
Legenda: P- Parque nacional Serra do Itajaí; I-ETA I; II - ETA II; III - ETA III;IV - ETA IV;COT - carbono orgânico total; e IC - carbono \\
inorgânico
\end{tabular}


com a ETA IV, tendo em vista as concentraçóes das espécies químicas monitoradas (Figura 5). Este fato é possivelmente causado pelo uso e da ocupação do solo nestas bacias, com predominância de manchas urbanas, indústrias e agricultura. Oliveira et al. (2014) analisando parâmetros físico-químicos dissolvidos (OD, DBO, pH e condutividade elétrica) nas bacias de drenagem dos rios Jundiaí e Capivari, também atestaram maiores concentraçôes no rio com maior influência antrópica, tendo como base indícios de carga poluidora proveniente do lançamento de esgotos domésticos e de atividades urbanas/industriais lançadas diretamente em suas águas. A ETA III e o parque nacional Serra do Itajaí, por apresentarem maiores áreas preservadas, apresentaram semelhanças em relação às suas concentraçóes. De Souza et al. (2014), analisando a importância da qualidade para múltiplos usos também encontraram resultados semelhantes em relação aos pontos de controle na bacia do Rio Almada (Sul da Bahia), sendo que o ponto a montante da cidade de Coaraci (mais preservado) foi o único com qualidade adequada para a modalidade de abastecimento urbano, pois não apresentava influência urbana direta, com altas concentraçóes de OD e baixas concentraçôes de turbidez, condutividade e fósforo total.
Os dados discutidos anteriormente foram em parte corroborados pelo resultado da análise de agrupamento, sendo que os mananciais da ETA I e ETA II são similares e agrupados com a ETA IV (Figura 6A), fato este que pode ser comprovado pelo uso do solo aproximadamente $55 \%$ antrópico para as ETA I e II e $68 \%$ para a ETA IV. A ETA III e o parque nacional Serra do Itajaí também possuem similaridades, possivelmente devido a área florestada, sendo a ETA III e o parque nacional Serra do Itajaí com respectivamente 97 e $99 \%$ de áreas de florestas nativas. Pinheiro et al. (2014) encontraram resultados semelhantes analisando a bacia do Ribeirão Garcia, sendo que os pontos de monitoramento com menos influência antrópica foram aqueles que apresentaram melhor desempenho em relaçáo a elementos descritores da qualidade de água.

As concentraçóes dos íons também apresentaram relações na análise de agrupamento entre magnésio, potássio, sulfato e cloreto (Figura 6B), também encontradas por Sun et al. (2014), e entre os elementos acetato e fosfato. As fortes correlaçóes entre magnésio e potássio indicam que estes elementos são derivados de uma fonte comum, e o sulfato e o cloreto são provenientes de uma segunda fonte de origem. As correlaçóes entre sulfato e cloreto em cursos de

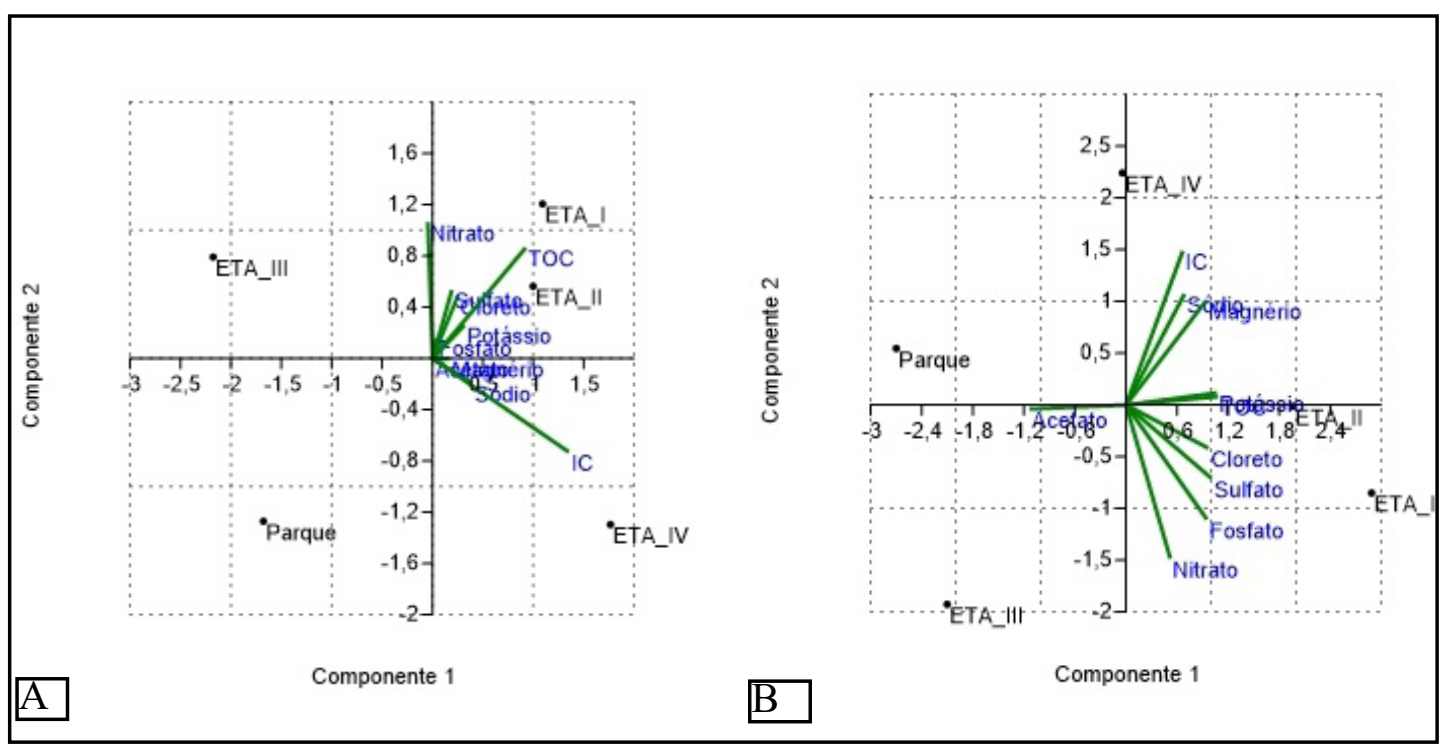

Figura 5 - Matriz (A) Var-covar e (B) correlação, da análise dos componentes principais em relação aos elementos químicos e águas de entrada das estações de tratamento de água de Blumenau, SC 


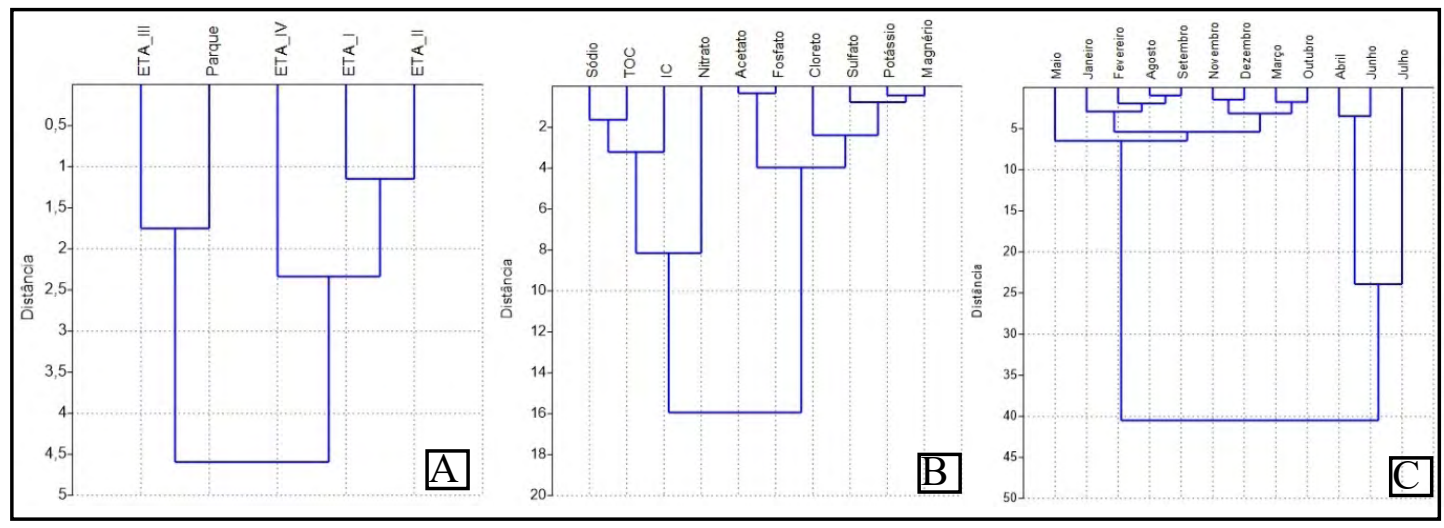

Figura 6 - Análise de agrupamento das médias dos parâmetros analisados para $(A)$ estações de tratamento de água, (B) concentrações e (C) meses do ano, Blumenau, SC-Brasil

água indicam principalmente de uma fonte antropogênica (Sun et al., 2014).

Em relação aos meses do ano (Figura 6C), houve a formação de dois grandes grupos, um com os meses abril, junho e julho, e outro grupo com formaçóes de subgrupos. Os subgrupos foram formados pelos meses: (a) janeiro, fevereiro, agosto e setembro; (b) novembro, dezembro, março e outubro; e (c) maio. O grande agrupamento com os meses de abril, junho e julho também foi divido em dois subgrupos: um com os meses de abril e junho, e outro com o mês de julho (responsável tanto por maiores concentraçóes e volumes de precipitação).

\section{CONCLUSÃO}

As águas dos mananciais das ETA I e II foram aquelas que apresentaram maiores concentraçóes das espécies químicas analisadas, sendo que a ETA II apresentou maior concentração para cloreto, sulfato, sódio e COT e a ETA I para nitrato, fosfato e potássio. As altas concentraçóes dessas bacias podem estar relacionadas com o tamanho da bacia (cerca de. $12.000 \mathrm{~km}^{2}$ ) e a diversidade de usos antrópicos (mancha urbana, agricultura, pastagens e solo exposto) que ocorrem a montante dessas estaçóes. A ETA IV apresentou maiores concentrações para os elementos magnésio e IC, possivelmente devido ao pequeno porte da bacia e a alta incidência de usos antrópicos como áreas urbanas e agricultura.
O parque nacional Serra do Itajaí apresentou maior concentraçáo apenas o acetato, que tem proveniência orgânica. Este elemento tem potencial de ser indicador de qualidade de água para bacias hidrográficas protegidas por florestas nativas. A ETA III não apresentou maiores concentraçóes para nenhum dos elementos analisados, ou seja, na bacia os elementos foram atenuados pela alta incidência de áreas de florestas nativas. Tendo em vista as concentraçóes dos elementos, as análises estatísticas empregadas neste estudo agruparam as ETAs I, II e IV, sendo que estas tiveram predominância de atividades antrópicas ao longo da área de drenagem. Náo foi encontrada forte correlação entre as concentraçóes dos elementos analisados e os meses do ano. Isto se deve, pois, o período analisado ainda é curto, náo podendo ser utilizado para configurar o comportamento anual (histerese) dos dados. Para isto seria necessária uma base de dados com no mínimo de dois a três anos de monitoramento.

Percebeu-se que as áreas com maior influência antrópica foram aquelas que apresentaram maior descaracterizaçáo da qualidade de água. Este fato poderia ser evitado se políticas públicas e regulamentaçôes de uso e ocupação do solo fossem eficientes e respeitadas pela comunidade. Uma forma de aumentar a eficiência destas medidas é fiscalização e penalização de infratores. A instalação de equipamentos de monitoramento por parte do poder público poderia auxiliar agências ambientais de monitoramento a melhorar o 
efetivo de fiscalização sobre a qualidade e saúde destes recursos.

Verificou-se que as ETA I e II são as estaçôes que mais necessitam esforços monetários e de ordem social para o seu devido tratamento. A ETA
III e o parque nacional Serra do Itajaí, por outro lado, foram aquelas que menos necessitariam investimentos para o tratamento, evidenciando que é mais rentável conservar as margens e áreas de preservação permanente do que melhorar os custos de tratamento.

\section{Referências}

ALVARES, C. A.; STAPE, J. L; SENTELHAS, P. C.; GONÇALVES, J. L. M.; PAROVEK, G. Köppen's climate classification map for Brazil. Meteorologische Zeitschrift, v. 22, p. 711-728, 2013.

APHA - AMERICAN PUBLIC HEALTH ASSOCIATION. Standard methods for the examination of water and wastewater. 20th edition. Washington DC USA: APHA, AWWA; WEF, 1998.

BRADY, N.C.; WEIL, R.R. The Nature and Properties of Soils. Prentice Hall, New Jersey, 2008.

BOWSER, C.J.; JONES, B.F. Mineralogic controls on the composition of natural waters dominated by silicate hydrolysis. American Journal of Science, v. 302, p. 582-662, 2002.

BUDAG, L. Vida coletiva e trocas sociais na área central de Blumenau/SC. Dissertação (Mestrado em Geografia). Florianópolis, SC, Universidade Federal de Santa Catarina. 2004.

BUENO, L. F.; GALBIATTI, J. A.; BORGES, M. J. Monitoramento de variáveis de qualidade da água do horto ouro verde - Conchal - SP. Engenharia Agrícola Jaboticabal, v. 25, n. 3, p.742-748, 2005.

CETESB - COMPANHIA AMBIENTAL DO ESTADO DE SÃO PAULO. Qualidade das águas interiores no estado de São Paulo série relatórios. Apêndice $D$ - significado ambiental e sanitário das variáveis de qualidade das águas e dos sedimentos e metodologias analíticas e de amostragem. Governo do estado de São Paulo e Secretaria do meio ambiente - Relatório - Apêndice A. 44 p, 2009. Disponível em: http://aguasinteriores.cetesb.sp.gov.br/wp-content/ uploads/sites/32/2013/11/Ap\%C3\%AAndice-D-Significado-Ambiental-e-Sanit\%C3\%A1rio-das-Vari\%C3\%A1veis-de-Qualidade.pdf

DIONEX, Achieving Low Baseline Noise for Anion Determinations by Suppressed Conductivity Using Carbonate Eluents. Dionex Aplication, D-Library, TN47, 2010a.

DIONEX. Determination of Inorganic Cations and Ammonium in Environmental Waters by lon Chromatography Using the IonPac ${ }^{\circledR}$ CS1 6 Column, Dionex Aplication, D-Library, AN 147, $2010 \mathrm{~b}$.

EPAGRI - EMPRESA DE PESQUISA AGROPECUÁRIA E EXTENSÃO RURAL DE SANTA CATARINA. Atlas Climatológico do Estado de Santa Catarina. Florianópolis. CD-ROM, 2002.

ESTEVES, F. A. Fundamentos de limnologia. Rio de Janeiro: Interciência, 826 p, 2011.

GUEDES, H. A. S.; SILVA, D. D. da; ELESBON, A. A. A.; RIBEIRO, C. B. M.; MATOS, A. T. de; SOARES, J. H. P. Aplicação da análise estatística multivariada no estudo da qualidade da água do Rio Pomba, MG. Revista Brasileira de Engenharia Agrícola e Ambiental, v. 16, n. 5, p. 558-563. 2012. 
IBGE, Instituto Brasileiro de Geografia e Estatística. Cidades: Blumenau. Disponível em: http://www.ibge.gov.br/cidadesat/ painel/painel.php?codmun $=420240 \#$.

KATZ, B.G. Influence of mineral weathering reactions on the chemical composition of soil water, springs, and ground water, Catoctin Mountains, Maryland. Hydrological Processes, v. 3, p. 185-202, 1989.

LUCAS, A. A. T.; MOURA, A. S. A.; NETTO A. O. A.; FACCIOLI, G. G.; SOUSA, I. F. Qualidade da água no riacho Jacaré, Sergipe Brasil usada para Irrigação. Revista Brasileira de Agricultura Irrigada, v.8, nº 2, p. 98 - 105, 2014.

LUOGON, M. S.; LOUZADA, F. L. R. O.; ROCHA, S. A. GARCIA, G. de. O.; SANTOS, A. R. dos. Diagnóstico ambiental da sub-bacia hidrográfica do córrego amarelo, abordando o uso e ocupação do solo e a qualidade da água. Engenharia Ambiental, v. 6, n. 3, p. 350-367, 2009.

MADRUGA, F. V.; REIS, F. A. G. V.; MEDEIROS, G. A. Avaliação da influência do córrego dos macacos na qualidade da água do rio Mogi Guaçu, no município de Mogi Guaçu, SP. Engenharia Ambiental, v. 5, n. 2, p. 152-168. 2008.

MARKEWITZ, D.; RICHTER, D.D. Long-term soil potassium availability from a Kanhapludult to an aggrading loblolly pine ecosystem. Forest Ecology and Management, v. 130, p. 109-129, 2000.

MONTEIRO, V. P.; PINHEIRO, J. C. V. Critério para implantação de tecnologias de suprimentos de água potável em municípios cearenses afetados pelo alto teor de sal. Economia Rural, v. 42, n. 2, p. 365-387. 2004.

MOURA, L. H. A.; BOAVENTURA, G. R.; PINELLI, M. P. A qualidade de água como indicador de uso e ocupação do solo: Bacia do Gama - Distrito Federal. Quim. Nova, v. 33, n. 1, p. 97-103. 2010.

NATURE. Mapa dos Remanescentes Florestais. Escala de mapeamento: 1:50.000. Sistema de projeção e sistema de referência: WGS 19841969 UTM Zone 22S. Secretaria de Estado da Agricultura e Desenvolvimento Rural - SAR (2005).

OLIVEIRA, H.; MORTATTI, J.; MORAES, G. M.; VENDRAMINI, D.; CAMPOS, K. B. G. Caracterização físico-química da carga dissolvida dos rios Jundiaí e Capivari, São Paulo. Geochimica Brasiliensis, v. 28, n.1, p. 23-35, 2014.

PETERS, N.E.; SHANLEY, J.B.; AULENBACH, B.T.; WEBB, R.M.; CAMPBELL, D.H.; HUNT, R., LARSEN, M.C.; STALLARD, R.F.; TROESTER, J.; WALKER, J.F. Water and solute mass balance of five small, relatively undisturbed watersheds in the US. Science of the Total Environment, v. 358, p. 221-242, 2006.

PINHEIRO, A.; PIAZZA, G. A.; ALVES, T. C.; AGUIDA, L. M.; KAUFMANN, V.; GOTARDO, R. Qualidade das Águas de uma Bacia Protegida por Floresta Ombrófila Densa. Revista Brasileira de Recursos Hídricos, v. 19, p. 101-117, 2014.

RICE, K.C.; BRICKER, O.P. Seasonal cycles of dissolved constituents in stream water in two forested catchments in the mid-Atlantic region of the eastern USA. Journal of Hydrology, v. 170, p. 137-158, 1995.

ROCHELLE, B.P.; CHURCH, M.R.; DAVID, M.R. Sulfur retention at intensively studied sites in the US and Canada. Water Air Soil Pollution, v. 33, p. 73-83, 1987. Disponivel em: 10.1007/BF00191379.

SAMAE - SERVIÇO AUTÔNOMO MUNICIPAL DE ÁGUA E ESGOTO. Estações de tratamento de água. Disponível em: <http://://www.samae.com.br>. 
Piazza G. A.;Grott S. C. ;Goulart J. A. G.;Kaufmann V. ¿ Caracterização espaço-temporal da qualidade...

SIMEONOV, V.; STRATIS, J. A.; SAMARA, C.; ZACHARIADIS, G.; VOUTSA, D.; ANTHEMIDIS, A.; SOFONIOU, M.; KOUIMTZIS, T. Assessment of the surface water quality in northern Greece. Water Research, v. 37, p. 119-124, 2003.

SOUZA, S. R; MELLO, F. R. Análise do uso e ocupação do solo em um trecho da zona norte do município de São José dos Campos - SP. Caderno de Geografia, v. 22, n. 37. 2012.

SOUZA, J. R.; MORAES, M. E. B.; SONODA, S. L.; SANTOS, H. C. R. G. A Importância da Qualidade da Água e os seus Múltiplos Usos: Caso Rio Almada, Sul da Bahia, Brasil. REDE - Revista Eletrônica do Prodema, v.8, n.1, p. 26-45, abr. 2014.

SUN, H.; ALEXANDER, J; GOVE, B.; PEZZI, E.; CHAKOWSKI, N.; HUSCH, J. Mineralogical and anthropogenic controls of stream water chemistry in salted watersheds. Applied Geochemistry, v. 48, p. 141-154, 2014.

\section{Ellen C. de O. Almeida Universidade Federal do Paraná,}

Curitiba, PR, Brasil. E-mail: ellencoa@gmail.com

Contribuição do autor:

Pesquisa de campo; análise laboratorial e dos dados; redação geral e fechamento do manuscrito.

\section{Caroline Kozak Universidade Federal do Paraná,}

Curitiba, PR, Brasil. E-mail: carolkozak05@gmail.com

Contribuição do autor:

análise laboratorial e dos dados; redaçâo e fechamento do manuscrito.

Luciane Lemos Prado Universidade Federal do Paraná,

Curitiba, PR, Brasil. E-mail: lucianeprado@ufpr.br

Contribuição do autor:

análise laboratorial e dos dados; revisão e fechamento do manuscrito.

Cristovão V. S. Fernandes Universidade Federal do Paraná,

Curitiba, PR, Brasil. E-mail: cris.dhs@ufpr.br

Contribuição do autor:

revisão e fechamento do manuscrito. 